Check for updates

Cite this: Chem. Sci., 2018, 9, 2797

Received 6th December 2017 Accepted 8th February 2018

DOI: $10.1039 / \mathrm{c} 7 \mathrm{sc} 05182 \mathrm{~d}$

rsc.li/chemical-science

\section{A red-shifted two-photon-only caging group for three-dimensional photorelease $\uparrow$}

\begin{abstract}
Yvonne Becker, $t^{a}$ Erik Unger, $t^{a}$ Manuela A. H. Fichte, ${ }^{a}$ Daniel A. Gacek, (DD b Andreas Dreuw, (D) Josef Wachtveitl, iD d Peter J. Wallab and Alexander Heckel (iD *a

Based on nitrodibenzofuran (NDBF) a new photocage with higher two-photon action cross section and red-shifted absorption was developed. Due to calculations, a dimethylamino functionality (DMA) was added at ring position 7. The uncaging of nucleobases after two-photon excitation (2PE) could be visualized via double-strand displacement in a hydrogel. With this assay we achieved three-dimensional photorelease of DMA-NDBF-protected DNA orthogonal to NDBF-protected strands. While being an excellent 2P-cage, DMA-NDBF is surprisingly stable under visible-light one-photon excitation (1PE). This case of excitation-specific photochemistry enhances the scope of orthogonal photoregulation.
\end{abstract}

\section{Introduction}

Over the last decades photolabile protecting groups (PPGs) became a frequently used tool to regulate bioactive molecules ${ }^{1}$ such as neurotransmitters, ${ }^{2-5}$ hormones $^{6,7}$ and even macromolecules like proteins ${ }^{8,9}$ and oligonucleotides. ${ }^{10-12}$

One crucial long-term goal is a red-shifting ${ }^{13}$ of the lightinduced photorelease (uncaging ${ }^{\mathbf{1 4}}$ ) into the therapeutic window ( 650-950 nm (ref. 15)). It is less harmless for living cells and deeper tissue penetration becomes possible in biological applications due to less absorption and scattering of e.g. blood..$^{16}$ In the 1990 s a promising (un)caging strategy for higher wavelengths (>650 nm) has emerged, based on two-photon (2P) sensitive photolabile groups. ${ }^{17-20}$ PPGs with 2P-absorption character are cleavable with femtosecond pulsed lasers. This non-linear optical process can be seen as a simultaneous absorption of two photons. In many cases - but not all ${ }^{21}-$ the resulting electronically excited state is the same when photons of half the energy are used. This process was first described by Maria Göppert-Mayer. ${ }^{22}$ It can be used to realize photochemistry with 3D spatial resolution since the excitation depends on the squared intensity $\left(p \sim I^{2}\right)$. Excitation volumes can be as small as a femtoliter. ${ }^{16}$ The 2 P-uncaging efficiency $\delta_{\mathrm{u}}$ can be described

\footnotetext{
${ }^{a}$ Goethe University Frankfurt, Institute for Organic Chemistry and Chemical Biology, Max-von-Laue-Str. 7, 60438 Frankfurt, Germany.E-mail: heckel@uni-frankfurt.de

${ }^{b}$ Technical University Braunschweig, Institute for Physical and Theoretical Chemistry, Gaußstr. 17, 38106 Braunschweig, Germany

'Interdisciplinary Center for Scientific Computing (IWR), Theoretical and Computational Chemistry, Im Neuenheimer Feld 205A, 69120 Heidelberg, Germany ${ }^{d}$ Goethe University Frankfurt, Institute for Physical and Theoretical Chemistry, Maxvon-Laue-Str. 7, 60438 Frankfurt, Germany

$\dagger$ Electronic supplementary information (ESI) available. See DOI: 10.1039/c7sc05182d

\$ These authors contributed equally to this work.
}

(analogous to the "quantum product" in 1P-uncaging) by the product of absorption cross section $\delta_{\mathrm{a}}$ and the uncaging quantum yield $\Phi_{\mathrm{u}}\left(\delta_{\mathrm{u}}=\delta_{\mathrm{a}} \cdot \Phi_{\mathrm{u}}\right) \cdot{ }^{16}$ The $\delta_{\mathrm{a}}$ of chromophores depends on the length and planarity of the $\pi$-electron system and substituent effects (i.e. push-pull-systems). ${ }^{16,23,24}$ The positions of the substituents are crucial: a dipolar character as well as quadrupolar or octupolar enhance the $2 \mathrm{P}$-absorption. ${ }^{23}$

In 2006, Ellis-Davies et al. introduced the new chromophore 3-nitrodibenzofuran (NDBF) for 2P-photolysis of NDBFEGTA: $\mathrm{Ca}^{2+}$ with $\delta_{\mathrm{u}}=0.6 \mathrm{GM}$ at $720 \mathrm{~nm}^{25}$

In this paper, based on the NDBF core (see compound $\mathbf{1}$, Fig. 1), we rationally designed and synthesized the dimethylamino derivate DMA-NDBF-OH (2, Fig. 1). Due to calculations with the DFT/B3LYP method and a $6-31 * \mathrm{G}$ basis set for the ground state equilibrium structures and TDDFT/BHLYP for exited states the dipolar structure should be red-shifted and have an increased $\delta_{\mathrm{a} \cdot}{ }^{26}$ Despite the availability of sophisticated computational methods the optimisation of 2P-chromophors remains a formidable challenge.

\section{Experimental and results}

The simulation of various NDBF derivatives predicted a preferred substitution of ring-position 7 with a dimethylamino (DMA) functionality as donor (Fig. 1). The expected

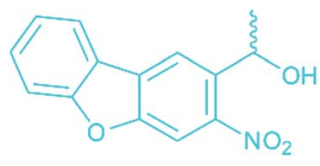

NDBF-OH (1)

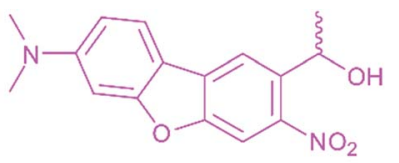

DMA-NDBF-OH (2)
Fig. 1 The caging group precursor NDBF-OH (1) and its new dimethylamino derivative DMA-NDBF-OH (2). 
uncaging efficiency of DMA-NDBF based on computed 2P-absorption spectra should be more than 20 times higher than the one of NDBF at its respective red-shifted maximum. ${ }^{26}$

\section{Small molecule synthesis and characterisation}

The synthesis of the caging group precursor DMA-NDBF-NH $\mathrm{N}_{2}(\mathbf{9})$ started with the iodation of 3-dimethyl-aminophenol (3) using $\mathrm{KI}$ and $\mathrm{KIO}_{3}$, followed by an electrophilic aromatic substitution to form 2-iodo-5-dimethylaminophenol (4) as summarised in Scheme 1. The unsymmetrical aryl ether 6 was formed via coupling with 4-fluoro-2-nitrobenzaldehyde (5) and subsequently reduced with trimethylaluminum. Hydrolysis led to alcohol 7, which was used for a palladium-catalysed intramolecular Heck-like reaction to yield the closed-ring form 2 . The azide 8 was synthesised under Mitsunobu conditions with in situ generated $\mathrm{HN}_{3}$. 8-(1-Aminoethyl)- $N, N$-dimethyl-7-nitrodibenzo- $[b, d]$ furan-3-amine 9 was finally obtained via Staudinger reaction.

For 1PE characterisation of DMA-NDBF-OH (2) an absorption spectrum was recorded (Fig. 2) in DMSO and compared to the one of unsubstituted NDBF-OH (1). The absorption maximum of 2 is shifted bathochromically from 312 to $424 \mathrm{~nm}$. With $15947 \mathrm{~L} \mathrm{~mol}^{-1} \mathrm{~cm}^{-1}$ at $424 \mathrm{~nm}$, the molar absorption is 98 times higher than the one of compound 1 (at $420 \mathrm{~nm}$ it is 79 times higher).

Then, 2P-fluorescence excitation (TPE) spectra of 1 and 2 were determined. Fig. 3 shows the relative fluorescence intensities observed in the visible spectral range $(\sim 400-700 \mathrm{~nm})$ after 2PE of 1 (cyan) and 2 (magenta) in DMSO using a wavelength range between 770 and $1060 \mathrm{~nm}$. We observed a generally higher responsiveness to $2 \mathrm{PE}$ for 2 than for 1 . The resulting fluorescence intensity for 2 at $840 \mathrm{~nm}$ e.g. is 40 times higher and should be proportional to the absorption cross section $\delta_{\mathrm{a}}$ of compound 2 . Of course, these 2 P-fluorescence excitation

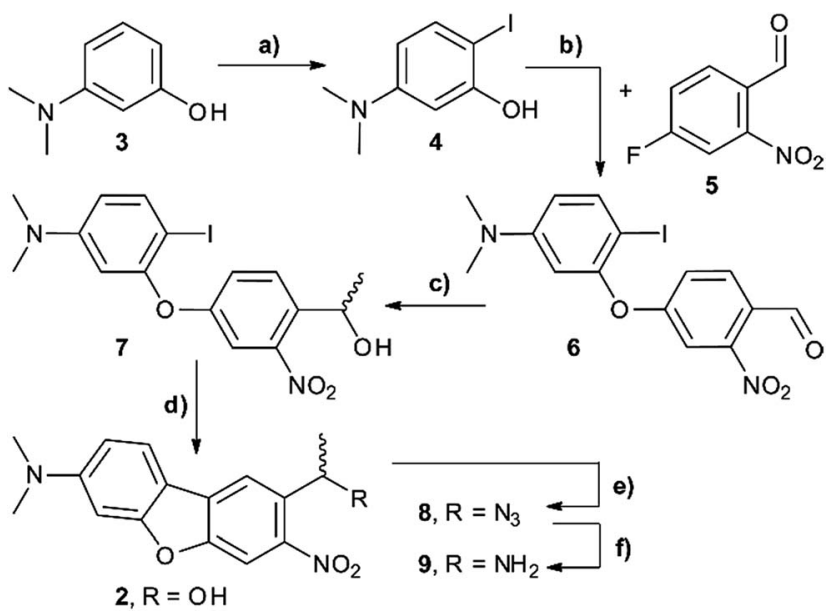

Scheme 1 Synthesis of photocage 9. (a) $\mathrm{KI}_{1} \mathrm{KIO}_{3}, 1 \mathrm{~N} \mathrm{H}_{2} \mathrm{SO}_{4}, \mathrm{H}_{2} \mathrm{O}, 3 \mathrm{~h}$, rt, 52\%. (b) KOtBu, DMSO, 63\%. (c) $\mathrm{Al}\left(\mathrm{CH}_{3}\right)_{3}, \mathrm{CH}_{2} \mathrm{Cl}_{2}, 30 \mathrm{~min}, \mathrm{O}^{\circ} \mathrm{C}, 97 \%$. (d) $\mathrm{Cs}_{2} \mathrm{CO}_{3}, \mathrm{Pd}(\mathrm{OAc})_{2}, \mathrm{H}_{2} \mathrm{O}, \mathrm{DMAc}, 3 \mathrm{~d}, 80{ }^{\circ} \mathrm{C}, 49 \%$. (e) $\mathrm{PPh}_{3}, \mathrm{HN}_{3}$ (in situ), DEAD, THF $12 \mathrm{~h}, 0^{\circ} \mathrm{C}->\mathrm{rt}, 93 \%$. (f) $\mathrm{PPh}_{3}, \mathrm{H}_{2} \mathrm{O}, \mathrm{THF} / \mathrm{MeCN}$ $(1: 1 \mathrm{v} / \mathrm{v}), 20 \mathrm{~h}, 70{ }^{\circ} \mathrm{C}->\mathrm{rt}, 71 \% . \mathrm{DMAc}=$ dimethylacetamide, $\mathrm{DEAD}=$ diethyl azodicarboxylate.

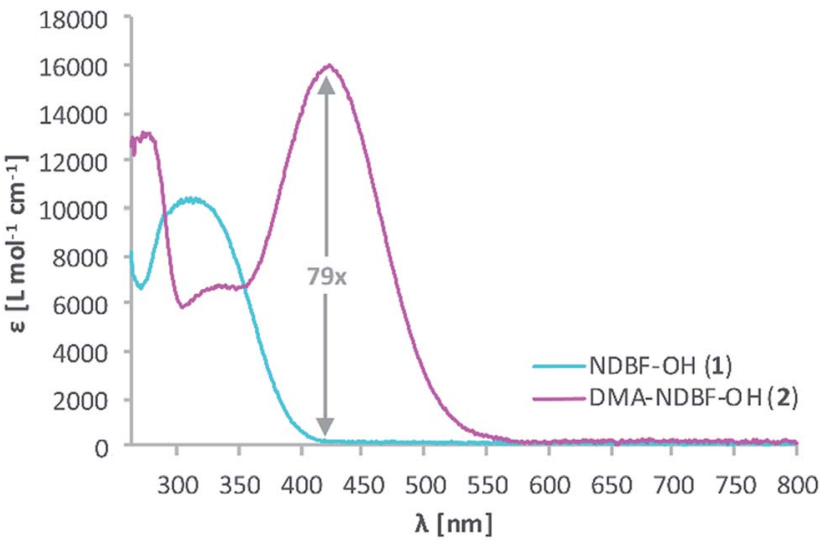

Fig. 2 Comparison of the 1P-absorption spectra of NDBF-OH (1, cyan) and its dimethylamino derivative DMA-NDBF-OH (2, magenta) in DMSO. The maximum is shifted bathochromically for photocage 2 due to addition of the $\mathrm{N}(\mathrm{Me})_{2}$ moiety and the absorption at $420 \mathrm{~nm}$ is 79 times higher.

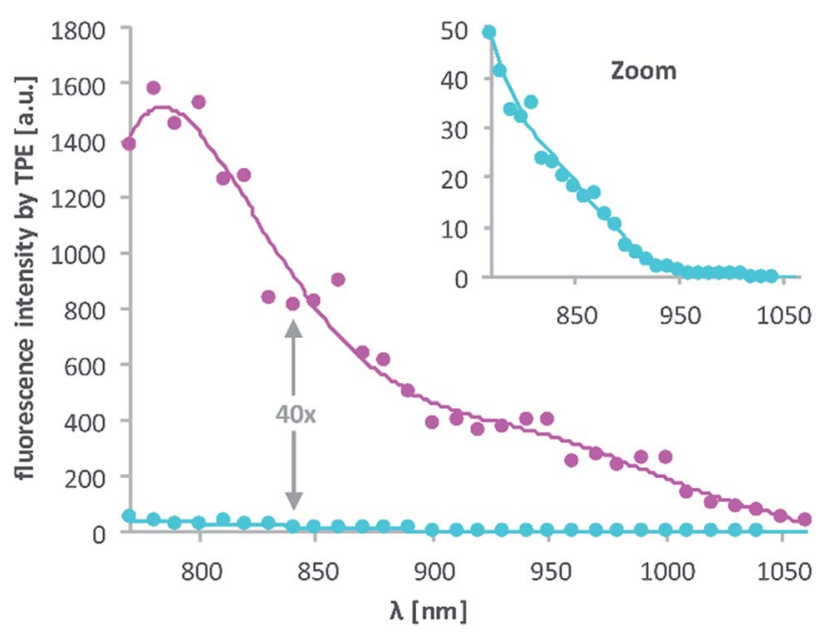

Fig. 3 Excitation spectra resulting from 2PE between 770 and $1060 \mathrm{~nm}$ of 1 and 2 in DMSO. The excitation power was set to $1.0 \mathrm{~mW}$ and squared dependence tested $(E S \mid+)$. Axes labelling for the "zoom" is the same. Solid lines are averages of the raw data (dots).

spectra do not directly reflect the $2 \mathrm{P}$-uncaging efficiency $\delta_{\mathrm{u}}$ as there is generally no direct relationship between a molecules fluorescence quantum yield $\Phi_{\mathrm{f}}$ and the quantum yield for the uncaging photochemistry $\Phi_{\mathrm{u}}$. However, the observation of high fluorescence intensities after two-photon excitation is a strong indication that compound $\mathbf{2}$ can indeed be two-photon excited quite readily, which is obviously a decisive prerequisite for any subsequent uncaging photochemistry (for more details see the discussion below and the ESI $\dagger$ ).

\section{Caged oligonucleotides synthesis and characterisation}

Scheme 2 summarises the synthesis of phosphoramidite 11 with the new DMA-NDBF caging group for oligonucleotide solid phase synthesis. Inosine was activated with 2,4,6-triisopropylbenzenesulfonyl chloride at the nucleobase and $3^{\prime}$ and $5^{\prime}-\mathrm{OH}$ 


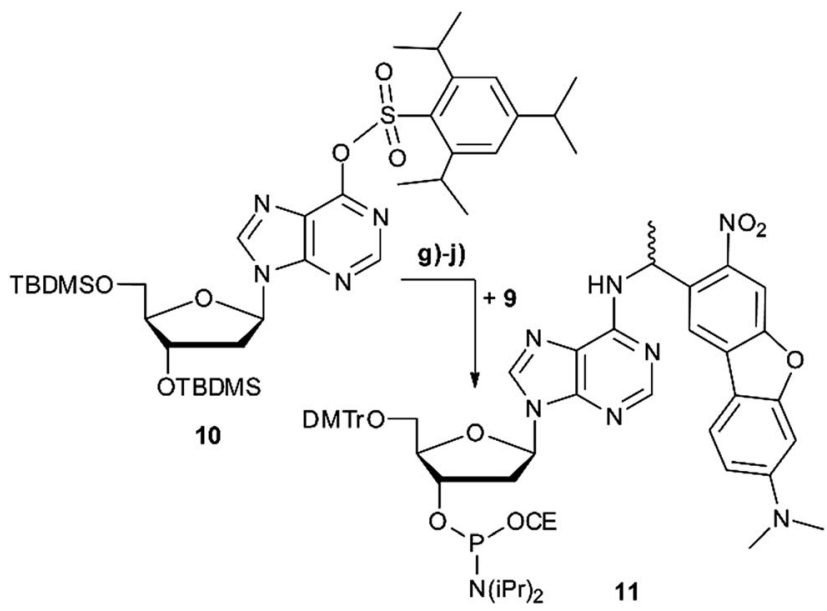

Scheme 2 Synthesis scheme of phosphoramidite 11 with new caging group 9. (g) 4-DMAP, DIPEA, DMF, 2 d, $90{ }^{\circ} \mathrm{C}, 62 \%$. (h) TBAF, THF, 2 h, rt, 98\%. (i) DMTrCl, pyridine, $12 \mathrm{~h}, \mathrm{rt}, 51 \%$. (j) DIPEA, 2-cyanoethyl- $N, N^{\prime}-$ diisopropylchlorophosphoramidite, $\mathrm{CH}_{2} \mathrm{Cl}_{2}, 2 \mathrm{~h}, \mathrm{rt}, 55 \%$. DMAP $=$ (dimethylamino)pyridine, DIPEA $=\mathrm{N}, \mathrm{N}$-diisopropylethylamine, $\mathrm{TBAF}=$ tetrabutylammonium fluoride.

protected with tert-butyldimethylsilyl (TBDMS) before it was reacted with 9, 4-DMAP and DIPEA in DMF. After a nearly quantitative TBAF-deprotection of the alcohols in THF the $5^{\prime}$ $\mathrm{OH}$ was protected with $4,4^{\prime}$-dimethoxytrityl (DMTr). Phosphoramidite $\mathbf{1 1}$ was obtained in a reaction with DIPEA and 2-cyanoethyl- $N, N^{\prime}$-diisopropylchlorophosphoramidite in $\mathrm{CH}_{2} \mathrm{Cl}_{2}$.

Photocages NDBF- $\mathrm{NH}_{2}$ and DMA-NDBF- $\mathrm{NH}_{2}$ (9) were introduced in three different sequences - resulting in five different DNA strands (see Table 1).

Test-sequences DNA1 and DNA2, 15-mers with the cage at position 8 , were used for first investigations of $1 \mathrm{P}$-absorption behaviour after irradiation (Fig. 4) and 1P-photolysis (Fig. 5). All irradiation-tests were performed with a concentration of $20 \mu \mathrm{M}$ in PBS.

Fig. 4a illustrates the absorption decrease of DNA2 with a dA ${ }^{\text {DMA-NDBF }}$ residue between 350 and $540 \mathrm{~nm}$ after irradiation with $365 \mathrm{~nm}$. The absorption of the nucleobases at around $260 \mathrm{~nm}$ remained unaffected. Quantification of caged and uncaged species could be performed subsequently via highperformance liquid chromatography (HPLC; Fig. 4b). With an internal standard (uracil) the amount of starting material could be determined - here demonstrated after irradiation $(365 \mathrm{~nm}$, $0.60 \mathrm{~mW}$ ) for 0,200 and 1200 seconds. The 1P-photolysis

Table 1 The five synthesised DNA strands used in this investigation

\begin{tabular}{|c|c|}
\hline Strand & $\begin{array}{l}\text { Sequence (dA caged with } x=\text { NDBF, } y=\text { DMA- } \\
\text { NDBF) }\end{array}$ \\
\hline DNA1 & $5^{\prime}$-GCATAAAA AAAGGTG-3' \\
\hline DNA2 & $5^{\prime}$-GCATAAAA A AAAGGTG-3' \\
\hline DNA3 & $5^{\prime}-\mathrm{SH}-\left(\mathrm{CH}_{2}\right)_{6}-\mathrm{GCA}^{\mathrm{x}} \mathrm{TAAA}^{\mathrm{x}} \mathrm{TAAA}^{\mathrm{x}}$ GGTG-3' \\
\hline DNA4 & 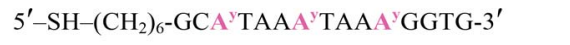 \\
\hline DNA5 & $5^{\prime}-\mathrm{SH}-\left(\mathrm{CH}_{2}\right)_{6}-\mathrm{AGA}^{\mathrm{x}} \mathrm{TACA}^{\mathrm{x}} \mathrm{GATA}^{\mathrm{x}} \mathrm{CGCA}-3^{\prime}$ \\
\hline
\end{tabular}

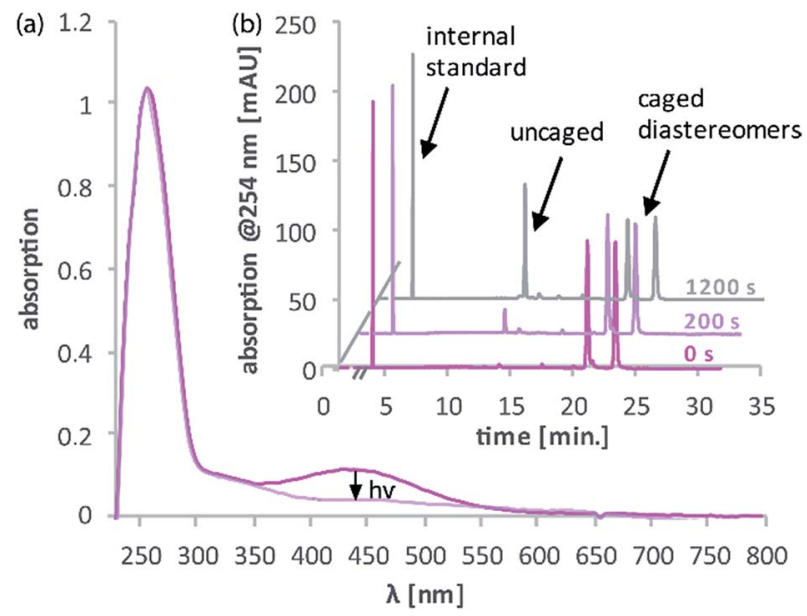

Fig. 4 (a) Decrease of absorption between approximately 350 and $540 \mathrm{~nm}$ due to irradiation of DNA2 with $\mathrm{dA} \mathrm{DMA}^{\mathrm{NDBF}}$ at position 8 and resulting uncaging $(0.9 \mathrm{nmol}, 45 \mu \mathrm{l}, 365 \mathrm{~nm}, 0.6 \mathrm{~mW})$. (b) HPLC analysis shows the reaction of the caged diastereomers $\left(t_{R}=21 \mathrm{~min}\right.$. and $23 \mathrm{~min}$.) and increase of the uncaged species ( $t_{R}=13 \mathrm{~min}$.) $(260 \mathrm{pmol}$, $13 \mu \mathrm{l}, 365 \mathrm{~nm}, 0.42 \mathrm{~mW}$ ). With $t_{\mathrm{R}}=$ retention time on chromatography column.

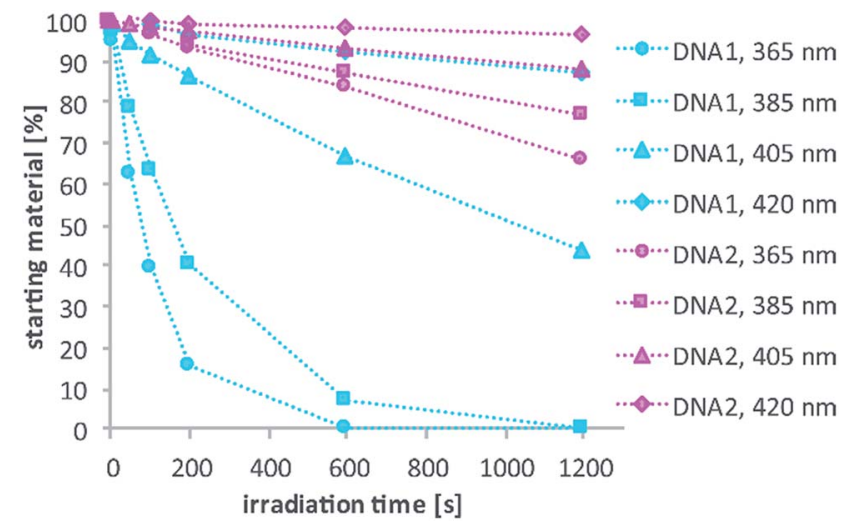

Fig. 5 Comparison of 1P-photolysis of DNA1 and DNA2 at various wavelengths but with the same number of photons per time. Conversion was determined by HPLC analysis. (260 pmol, $13 \mu \mathrm{l}$, $0.42 \mathrm{~mW}$ in case of $365 \mathrm{~nm}$ irradiation).

behaviour was tested for DNA1 and DNA2 at various wavelengths as shown in Fig. 5. The samples were irradiated for up to 1200 seconds at $365(0.42 \mathrm{~mW}), 385(0.40 \mathrm{~mW}), 405(0.38 \mathrm{~mW})$ or $420 \mathrm{~nm}(0.37 \mathrm{~mW})$. For comparison, the number of photons per time was kept constant.

The 1P-photolysis of DNA1 was found to be significantly faster at every tested wavelength compared to DNA2. For example, after $1200 \mathrm{~s}$ irradiation at $385 \mathrm{~nm}$ DNA1 was quantitatively uncaged, whereas $77 \%$ starting material remained in case of DNA2. After the same time of irradiation at $420 \mathrm{~nm}$ we observed $87 \%$ remaining starting material for DNA1 and $97 \%$ of DNA2, even though DMA-NDBF has its absorption maximum at $424 \mathrm{~nm}$. Further experiments revealed that with wavelengths $>420 \mathrm{~nm}$ (i.e. $455 \mathrm{~nm}$ ) no 1P-photolysis could be detected at all for DNA2 - regardless of the power we used! The 1P-quantum 
yield $\Phi^{\prime}{ }_{420}$ for DNA1 with a dA ${ }^{\mathrm{NDBF}}$ residue was found to be $13.6 \%$ and for DNA2 with $\mathrm{dA}^{\text {DMA-NDBF }} 0.05 \% .{ }^{27}$ The respective quantum yields $\Phi_{340}^{\prime}$ were $24.05 \%$ and $1.10 \%$, showing that irradiation into the transition of DMA-NDBF at around $340 \mathrm{~nm}$ results in some extent of uncaging whereas the lower-energy transition does not (see also ESI $\dagger$ for a more detailed analysis).

Compound 2 shows some similarity to an amino-substituted ortho-nitrobenzyl caging group which has been investigated by Bochet et al. ${ }^{28}$ In their case only prior protonation of the amino group led to a state with productive photolysis while irradiation into the unprotonated state yielded a charge transfer transition instead of uncaging. Investigations addressing the charge transfer character in the photochemistry of compound 2 can be found in the ESI. $\dagger$ However, even at $\mathrm{pH} 2$ there was no conversion of DNA2 upon irradiation at $455 \mathrm{~nm} .^{29}$

For the 2-photon-characterisation of the photocages in DNA strands we used our recently published hydrogel-fluorescenceassay on a confocal microscope and laser setup (ESI $\dagger$ ). ${ }^{30,31}$ DNA3 and DNA4 with either $\mathrm{dA}^{\mathrm{NDBF}}$ or $\mathrm{dA}^{\text {DMA-NDBF }}$ residues, respectively, were immobilised via thiol-linkers in a hydrogel (PVA-PEG), as illustrated in Scheme 3. Then the gel was soaked with a buffered solution containing a duplex of a 15-mer-strand with a $5^{\prime}$-terminally attached fluorophore (ATTO565) and a $3^{\prime}$-quencher (BHQ2) 11-mer strand. The quencher strand displacement after uncaging of DNA3 or DNA4 led to increased fluorescence in the focal plane. The uncaging-wavelengths between 720 and $980 \mathrm{~nm}$ were generated with a pulsed Ti:sapphire laser for 2P-excitation. For each of the wavelengths investigated one line was written into the hydrogel (Fig. 6b) and the resulting fluorescence was quantified (Fig. 6a). The power was kept constant for every line. The form of the pink spectrum in Fig. 6a (with a maximum at $840 \mathrm{~nm}$ ) resembles very much the one of the pink spectrum in Fig. 2 (with a maximum at $424 \mathrm{~nm}$ ). However, 1P-irradiation at $420 \mathrm{~nm}$ results in a poor conversion whereas 2 P-irradiation at $2 \times 420 \mathrm{~nm}$ efficiently produces the desired uncaged product strand.

Apparently, DMA-NDBF is one of the few cases where 1PE and $2 \mathrm{PE}$ with twice the wavelength do not result in the same photochemical behaviour. In our case, the excited state after 1PE appears to have a low uncaging quantum yield, i.e. this caging group can be considered as "one-photon-stable" (at least

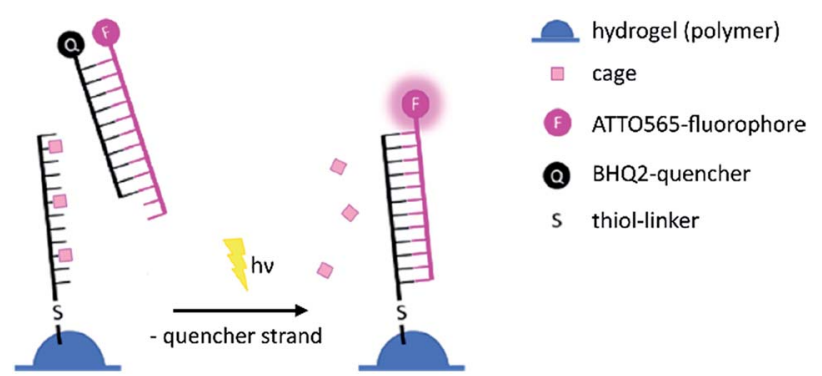

Scheme 3 Hydrogel-fluorescence-assay to monitor uncaging. After irradiation with a defined wavelength the triply caged antisense strand becomes uncaged and is able to bind the $5^{\prime}$-fluorophore-labelled strand. By competition, the counter strand with the quencher is removed, the fluorescence increases.

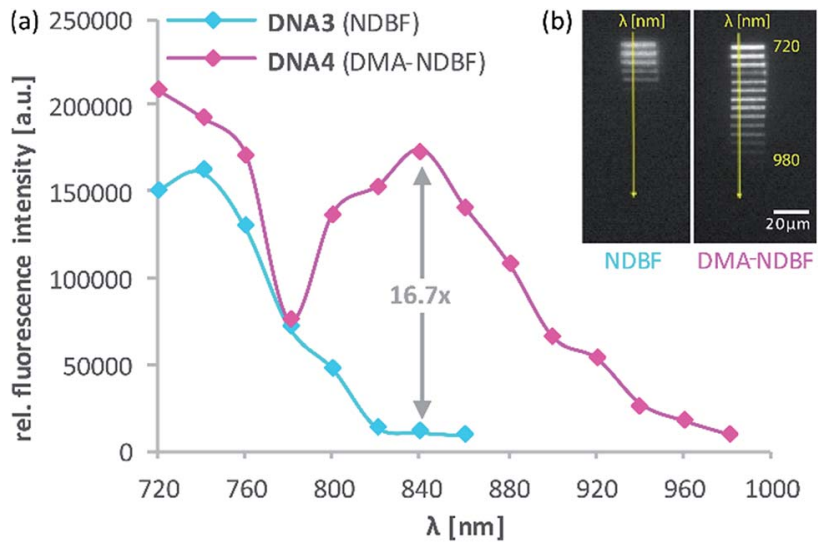

Fig. 6 (a) 2P-activation of fluorescence (ATTO565) with NDBF and DMA-NDBF, based on (b) intensity measurements in a hydrogel after uncaging at the indicated wavelengths. DMA-NDBF has a red-shifted local maximum at $840 \mathrm{~nm}$.

in the visible range) whereas after $2 \mathrm{PE}$ the intended uncaging reaction readily occurs with irradiation conditions that have been shown to be compatible with living cells. ${ }^{30}$

Because of its low 1P-photolysis rates, we decided to use DMA-NDBF as a "2P-only-cage" which should be applicable for complex orthogonal uncaging together with various $1 \mathrm{P}$-cages especially also red-shifted ones that are currently the focus of much attention. We used DNA4 with $\mathrm{dA}^{\text {DMA-NDBF }}$ residues and DNA5 with a different sequence and $\mathrm{dA}^{\mathrm{NDBF}}$ residues for individual addressing together in the same hydrogel. For a twocolour read-out ATTO565 and ATTORho14 were used as fluorophores F1 and F2 and BHQ2 (Q1) and BBQ-650III (Q2) as matching quencher pairs (for an overview see Scheme $\mathrm{S} 2$ in the ESI $\dagger$ ). Fig. 7 provides an overview of optimised irradiationconditions, tested for the triply caged strands. With $420 \mathrm{~nm}$ (1PE, $780 \mathrm{nW}, 2$ scans) it was possible to only uncage the NDBF, with $730 \mathrm{~nm}$ (2PE, $15 \mathrm{~mW}, 5$ scans) both - however DMA-NDBF much more efficiently than NDBF - and $840 \mathrm{~nm}$ (2PE, $15 \mathrm{~mW}, 5$ scans) only DMA-NDBF, while leaving the other cage intact in the same hydrogel. Based on these results, seven rectangular shapes (steps) were written into the hydrogel with $840 \mathrm{~nm}$ (Fig. 8), as well as a circular shape with $420 \mathrm{~nm}$. The laser beam

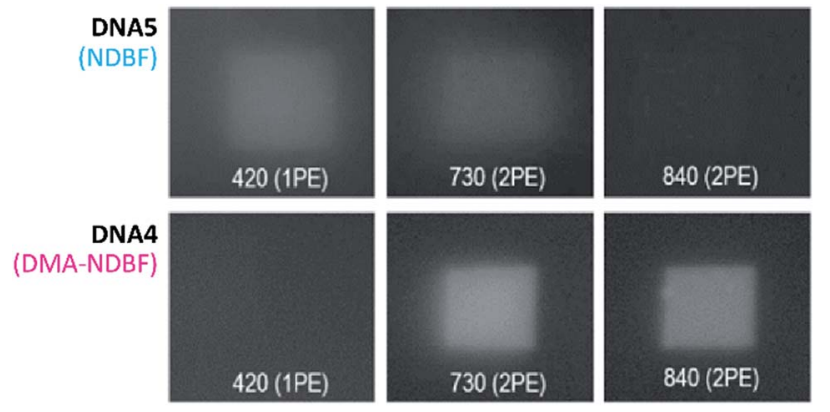

Fig. 7 Tests with the triply caged DNA4 and DNA5 for optimised uncaging-orthogonality. The best results were obtained with $420 \mathrm{~nm}$ with $780 \mathrm{nW}$ and 2 scan repeats, $730 \mathrm{~nm}$ and $840 \mathrm{~nm}$ with $15 \mathrm{~mW}$ and 5 scans. 

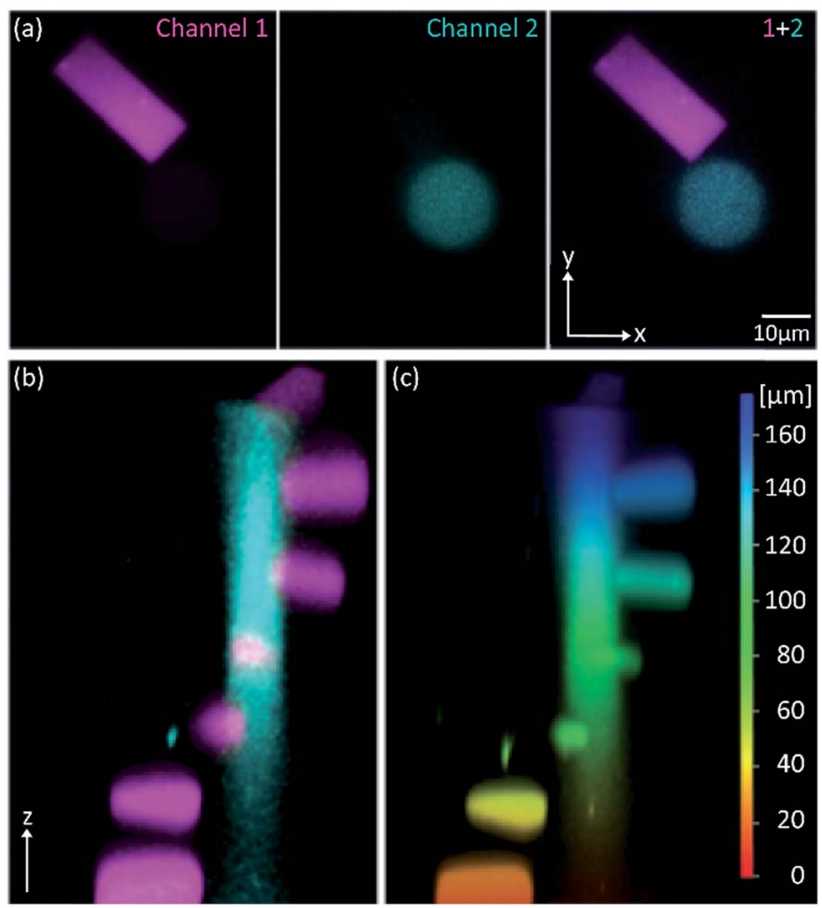

Fig. 8 3D picture of a winding staircase with a one-photon uncaging $(420 \mathrm{~nm})$ core and two-photon $(840 \mathrm{~nm})$ steps. (a) Channel 1, channel 2 and combination in $x$-/y-plane and (b) $z-/ y$-plane. (c) Colour-coded height profile of the $z-/ y$-plane $(0-160 \mu \mathrm{m})$.

direction followed the $z$-axis. The $2 \mathrm{P}$-steps with spatial resolution in $z$ had a distance of $25 \mu \mathrm{m}$ between them. The circular 1Pirradiation resulted in the cylindrical staircase core shown in Fig. 8. A z-stack (Fig. S4†) with two detection channels (Ch. 1: fluorescence excitation $543 \mathrm{~nm}$, detection at 557-612 nm; Ch. 2: excitation $633 \mathrm{~nm}$, detection 671-721 nm) was imaged at laser setup 2 (ESI $\dagger$ ). Fig. 8a shows the magenta-channel 1, cyanchannel 2 and the overlaid combination in the $x / y$-plane. For Fig. $8 \mathrm{~b}$ and $\mathrm{c}$ the staircase was rotated in the $z$ - $/ y$-plane. The colours in Fig. $8 \mathrm{c}$ demonstrate the height in the hydrogel. The laser powers used were in a range compatible with living cells. For instance, 18-24 $\mathrm{mW}$ were found to be tolerated by HEK cells, dorsal root ganglia and liver cells for 10-20 scans. ${ }^{32}$

\section{Conclusion}

In summary we designed, synthesised, and characterised a new dimethylamino derivative of the NDBF photolabile protecting group (PPG). It shows a red-shifted one- and two-photon absorption compared to the NDBF group - which is important for biological applications. As predicted by theoretical calculations the DMA-NDBF PPG shows a better two-photon photolysis behaviour compared to NDBF. However, to our surprise it turned out that the one-photon photolysis efficiency of DMANDBF is rather poor, especially for wavelengths beyond $400 \mathrm{~nm}$. Based on our calculations we propose that this is a rare case of excitation-specific photochemistry. Both 1PE and 2PE at twice the wavelength populate the same excited state, since the $\mathrm{S}_{1}$ exhibits substantial one-photon oscillator strength as well as two-photon absorption cross section. $^{26}$ However, different photochemical behaviour is induced, because $1 \mathrm{PE}$ and $2 \mathrm{PE}$ electronic excitations couple to different molecular vibrations. ${ }^{33}$ This unusual "two-photon-only" behaviour offers interesting applications for light-regulation scenarios with increased complexity. We had recently presented orthogonal two-colour, two-photon uncaging ${ }^{30}$ where we had to carefully control the two-photon irradiation conditions (especially the power). With DMA-NDBF, we can now perform efficient two-photon uncaging with red light leaving a broad spectral window open for orthogonal 1P-uncaging in the red part of the spectrum. In addition, 1PE can now be performed before 2PE with DMADNBF, which is surprisingly "one-photon-stable". With previous two-photon caging groups, the $2 \mathrm{PE}$ had to be performed as first photochemical operation. This adds another degree of freedom to ever more complex scenarios of complex light control. ${ }^{34,35}$ Its one-photon-stability and yet easy and selective photolysis under $2 \mathrm{PE}$, its red-shifted $2 \mathrm{P}$ absorption which lies perfectly in the therapeutic window and its perfect stability to regular ambient light make the DMA-NDBF a very interesting caging group for future biological applications.

\section{Conflicts of interest}

There are no conflicts of interest to declare.

\section{Acknowledgements}

This research was funded by the Deutsche Forschungsgemeinschaft (GRK 1986-CLiC). We gratefully acknowledge the help of the Heilemann group (Goethe-University Frankfurt).

\section{Notes and references}

1 P. Klán, T. Solomek, C. G. Bochet, A. Blanc, R. Givens, M. Rubina, V. Popik, A. Kostikov and J. Wirz, Chem. Rev., 2013, 113, 119-191.

2 F. Palma-Cerda, C. Auger, D. J. Crawford, A. C. Hodgson, S. J. Reynolds, J. K. Cowell, K. A. Swift, O. Cais, L. Vyklicky, J. E. Corrie and D. Ogden, Neuropharmacology, 2012, 63, 624-634.

3 A. C. Rea, L. N. Vandenberg, R. E. Ball, A. A. Snouffer, A. G. Hudson, Y. Zhu, D. E. McLain, L. L. Johnston, J. D. Lauderdale, M. Levin and T. M. Dore, Chem. Biol., 2013, 20, 1536-1546.

4 R. Cabrera, O. Filevich, B. García-Acosta, J. Athilingam, K. J. Bender, K. E. Poskanzer and R. Etchenique, ACS Chem. Neurosci., 2017, 8, 1036-1042.

5 M. T. Richers, J. M. Amatrudo, J. P. Olson and G. C. R. EllisDavies, Angew. Chem., Int. Ed., 2017, 56, 193-197.

6 F. G. Cruz, J. T. Koh and K. H. Link, J. Am. Chem. Soc., 2000, 122, 8777-8778.

7 W. Lin, C. Albanese, R. G. Pestell and D. S. Lawrence, Chem. Biol., 2002, 9, 1347-1353.

8 S. Tang, Z. Wan, Y. Gao, J.-S. Zheng, J. Wang, Y.-Y. Si, X. Chen, H. Qi, L. Liu and W. Liu, Chem. Sci., 2016, 7, 1891-1895. 
9 J. Hemphill, E. K. Borchardt, K. Brown, A. Asokan and A. Deiters, J. Am. Chem. Soc., 2015, 137, 5642-5645.

10 C. Brieke, F. Rohrbach, A. Gottschalk, G. Mayer and A. Heckel, Angew. Chem., Int. Ed., 2012, 51, 8446-8476.

11 S. B. Yeldell, B. K. Ruble and I. J. Dmochowski, Org. Biomol. Chem., 2017, 15, 10001-10009.

12 T. Lucas, F. Schäfer, P. Müller, S. A. Eming, A. Heckel and S. Dimmeler, Nat. Commun., 2017, 8, 15162.

13 I. Aujard, C. Benbrahim, M. Gouget, O. Ruel, J.-B. Baudin, P. Neveu and L. Jullien, Chem.-Eur. J., 2006, 12, 6865-6879.

14 H. Kaplan, B. Forbush III and J. F. Hoffman, Biochemistry, 1978, 17, 1929-1935.

15 L. Shi, L. A. Sordillo, A. Rodríguez-Contreras and R. Alfano, J. Biophotonics, 2016, 9, 38-43.

16 M. Abe, Y. Chitose, S. Jakkampudi, P. T. T. Thuy, Q. Lin, B. T. Van, A. Yamada, R. Oyama, M. Sasaki and C. Katan, Synthesis, 2017, 49, 3337-3346.

17 W. Denk, J. H. Strickler and W. W. Webb, Science, 1990, 248, 73-76.

18 W. Denk, Proc. Natl. Acad. Sci. U. S. A., 1994, 91, 6629-6633. 19 P. Lipp and E. Niggli, E. J. Physiol., 1998, 508(3), 801-809.

20 T. Furuta, S. S. Wang, J. L. Dantzker, T. M. Dore, J. W. Bybee, E. M. Callaway, W. Denk and R. Y. Tsien, Proc. Natl. Acad. Sci. U. S. A., 1999, 96, 1193-1200.

21 D. A. Gacek, A. L. Moore, T. A. Moore and P. J. Walla, J. Phys. Chem. B, 2017, 121, 10055-10063.

22 M. Göppert-Mayer, Ann. Phys., 1931, 401, 273-294.

23 F. Terenziani, C. Katan, E. Badaeva, S. Tretiak and M. Blanchard-Desce, Adv. Mater., 2008, 20, 4641-4678.
24 M. J. Davis, C. H. Kragor, K. G. Reddie, H. C. Wilson, Y. Zhu and T. M. Dore, J. Org. Chem., 2009, 74, 1721-1729.

25 A. Momotake, N. Lindegger, E. Niggli, R. J. Barsotti and G. C. R. Ellis-Davies, Nat. Methods, 2006, 3, 35-40.

26 A. Dreuw, M. A. Polkehn, R. Binder and A. Heckel, J. Comput. Chem., 2012, 33, 1797-1805.

27 Determined using ferrioxalate actinometry, Current Protocols in Nucleic Acid Chemistry, ed. A. Rodrigues-Correia, P. Seyfried and A. Heckel, John Wiley \& Sons Inc., New York 2014, unit 6.11.

28 E. Riguet and C. G. Bochet, Org. Lett., 2007, 9, 5453-5456.

29 The $\mathrm{p} K_{\mathrm{a}}$ of DMA-NDBF-OH (2) for the protonation of the dimethylamino group was estimated to be 4.0 using ACD/ Labs Percepta.

30 M. A. H. Fichte, X. M. M. Weyel, S. Junek, F. Schäfer, C. Herbivo, M. Goeldner, A. Specht, J. Wachtveitl and A. Heckel, Angew. Chem., Int. Ed. Engl., 2016, 55, 8948-8952.

31 Q. Li, G. Luan, Q. Guo and J. Liang, Nucleic Acids Res., 2002, 30, e5.

32 N. I. Kiskin, R. Chillingworth, J. A. McCray, D. Piston and D. Ogden, Eur. Biophys. J., 2002, 30, 588-604.

33 P. Macak, Y. Luo and H. Ågren, Chem. Phys. Lett., 2002, 330, 447-456.

34 A. Rodrigues-Correia, X. M. M. Weyel and A. Heckel, Org. Lett., 2013, 15, 5500-5503.

35 V. San Miguel, C. G. Bochet and A. del Campo, J. Am. Chem. Soc., 2011, 133, 5380-5388. 